\title{
Ecology-Based Gymnasium Design
}

\author{
Zhang Zhan-Yi*
}

College of Physical Education of Henan Normal University, Xinxiang 453007, China

\begin{abstract}
With the continuous development of sports, gymnasium design now becomes the focus of design. In order to optimize gymnasium design, the design form should be innovated based on current design stance, so as to design new gymnasium consistent with current development trend. To construct ecology-based gymnasium, the optimized analysis on construction mode should be made in strict accordance with ecology and sports knowledge and in combination with the design concept and development orientation of gymnasium, according to, so as to make sports buildings sustainable. This paper, with the focus of study on relevant ecological theory, is to make detailed analysis on the optimization of gymnasium design.
\end{abstract}

Keywords: Design concept, ecology-based, gymnasium design.

\section{INTRODUCTION}

In recent years, the development concept that sports and ecology exist harmoniously enjoys popular support. Hence, the design of gymnasium should give expression to the harmonious existence of human beings and ecology, and the harmoniousness of human beings and the society. However, affected by other factors, contamination is becoming a major factor which threatens people's health and living quality. Therefore, people gradually attach importance to environmental protection. Affected by all big backgrounds, ecologic energy saving technology is of essential significance [1]. Sports buildings are affiliated to public buildings, mainly characterized by bulk mass, high running cost and relatively huge energy saving potential. Exploring ecologic energy saving potential of sport buildings will make a significant contribution to energy saving and environmental protection of public buildings.

\section{THEORETICAL PROBLEMS ON PE ECOLOGY}

\subsection{Explanation On PE Ecology Concept}

Ecology is a subject in relation to the interaction between organics and the environment, and the environment here means physical environment and ecologic environment. Physical environment includes temperature, water, wind, etc. and ecologic environment involves the influence of organics and inorganics on other factors. From the perspective of ecology and PE, in order to have an all-round knowledge on $\mathrm{PE}$ ecology, people are required to get necessary substance through cautious and reasonable ways of PE, so as to realize sustainable development of PE, culture and economy.

\subsection{Principle Of PE Ecology}

The fundamental principle of PE ecology can be divided abstractly into substance, energy and information. In practice, people are required to know about optimal principle from the respective of space, time and quantity. Since creature and environment form a single structure and PE ecology is based theoretically on somatic science, sports science and ecologic science should be combined organically in design process to facilitate the application and transformation of human's energy in the process of ecological environment movement [2]. A school here is taken for example to analyze the design level of ecology-based gymnasiums. See Table 1.

\subsection{Significance Of Ecology-based Gymnasium Design}

With the continuous progress of times, ecologic benefits and ecologic awareness are gradually concerned by politicians and economists. Entrepreneurs also emphasize ecological environment. However, with the constant adjustment of natural environment, ecologic harmoniousness has become the focus of current management. As the main body of buildings, sports buildings involve numerous factors, hence, design concept should be strengthened in practice.

Since the building criteria improves gradually, high technology plays more and more important roles and buildings are affected by more and more factors. By reason of lacking natural lighting and fresh air, reified analysis should be made for design form. As physical exercise in sunlight and air are gradually far away from the natural attribute and the essence of life, therefore, design workload is increased invisibly.

\section{ECOLOGY-BASED GYMNASIUM DESIGN STRATEGY}

\subsection{Ecologicalization of Sports Building In Design}

The eco-design of sports buildings should consciously balance the relation between environmental resources and construction, start from overall venue environment design, 
Table 1. Ecologic assessment index system.

\begin{tabular}{|c|c|c|}
\hline Level I Index & Level II Index & Level III Index \\
\hline \hline School environment & Quantity of sports fields & Percentage of sports projects and total amount of exercise \\
\hline Artificial environment & Quantity of sports fields & Set as per different requirements \\
\hline Social environment & Environment of gymnasium & Economic input on sports facilities \\
\hline
\end{tabular}

Table 2. Analysis on eco-design mode.

\begin{tabular}{|c|c|c|c|}
\hline Influence Factor & Environmental Design & Functional Space & Technical Materials \\
\hline \hline Design concept & Integration & Automation & All-round \\
\hline Design structure & Coverage & Fusion & Merger \\
\hline
\end{tabular}

Table 3. Analysis on ecological interface.

\begin{tabular}{|c|c|c|c|}
\hline Ecological Interface & Double Roofs Design & Double-Skin Facades Strategy & Comprehensive Consistency Strategy \\
\hline \hline Basic functions & Ventilation and lighting & Protecting against cold & Dampproof and sunproof \\
\hline Communication way & Commonality & Transparency & Communicativeness \\
\hline
\end{tabular}

functional space, technical materials, etc., and make reasonable analysis as per integrated design concept [3, 4]. The detail presentations are shown in Table 2.

\subsection{Ecological And Energy Saving Strategy of Sports Buildings}

The ecology and energy saving of sports buildings are reflected in multiple aspects, comprehensive analysis on the application of energy should be done as per the application mode and design procedure of architectural interface. Due to the indistinct regionalism of sports buildings, the regionalism is at recessive state in a long time, however, by reason of the essential difference between architectural structure and geographic environment, regional culture factor should be analyzed in detail and key factor should be extracted, which is of great importance for the forming of personality and feature.

\subsubsection{Strategic Analysis on Ecological Interface}

Since sports buildings are large-scale public buildings, ecological conditions and the involved factors should be analyzed in detail. Because open environment involves natural environment and other factors, double-layered strategic analysis is very important in design process, including lighting, ventilating, protecting against cold, etc. To ensure lighting needs, internal and external communication way and application level should be analyzed, so as to highlight commonality and transparent thoughts. See Table $\mathbf{3}$ for introduction to detailed interface.

To ensure the reasonability of ecological design, full advantages of interface design hierarchy should be taken, proper selection and design should be made according to the impact of different climates and geographic conditions, and strategy analysis on optimization mode should be done, so as to bring the characteristics of materials into full play to meet basic functional demands [5].

\subsubsection{Usage of Non-Renewable Resources}

Energy problem roots in environment crisis, so great attention to ecological environment should be paid in design process. Solar energy resource is a sort of resource with wide application currently. Natural factors should be brought into full play to analyze environmental factors.

\subsubsection{Analysis on Integrated Design Mode}

In preliminary design, architects are required to make recombination analysis on ecological structure reasonably to avoid unnecessary waste. A systematic analysis will be made here on the optimized design of gymnasiums in cold area. Since the reasonability of exterior wall design and structure is considered, energy-saving mechanical equipment, power system and reclaimed water system should be used and the thermal performance of exterior wall materials should be considered to reduce the use of air conditioning system and save energy. Simultaneously, the application of materials is also a very important problem, so a comprehensive consideration for sports building can bring convenience to the future use and also reduce unnecessary waste.

Sustainable development concept is the ideal objective for organic integration of sports and environmental protection. In practice, from the perspectives of sports, economy and humanity, all sides should be united into architectural design and reasonable development orientation and objectives should be planned. More importantly, ecological and energy saving and sustainable development concept should 
Table 4. Analysis on detailed energy saving techniques.

\begin{tabular}{|c|c|c|c|}
\hline Type of Technique & Design Energy Saving & Equipment Energy Saving & Renewable Energy Sources \\
\hline \hline Design objective & Energy saving and ventilation & Design for reduction & Illumination control \\
\hline Way of control & Solar energy & Wind energy & Geothermal energy \\
\hline
\end{tabular}

Table 5. Analysis on gymnasium design size under multi-environment influence.

\begin{tabular}{|c|c|c|c|}
\hline Number & Length (m) & Span (m) & Height (m) \\
\hline \hline G1 & 44 & 26.5 & 16.5 \\
\hline G2 & 54.8 & 52.1 & 16.4 \\
\hline G3 & 68 & 63.9 & 16.8 \\
\hline G4 & 67.2 & 78.8 & 19.5 \\
\hline G5 & 81.5 & 78.5 & 19.8 \\
\hline G6 & 84.8 & 88.6 & 20.6 \\
\hline
\end{tabular}

be reflected in design process. To better designer's conception, breakthroughs in the original single design mode and design conception should be made, so as to study the design and development trend of sports buildings with a broader view. See Table 4 for detailed energy saving techniques.

In detailed design process, architects are required to make reasonable analysis on each structure of gymnasiums, so as to reach the objective of energy saving design, including the layout and orientation of buildings, the opening form of entrance hall, sunshading, etc., the application of architectural plane, structure functionalization, natural ventilation, design for reduction of equipment, such as air conditioners and lighting devices, etc. Since the design effect relies upon the relevant equipment, hardware factors should be considered in the process of high-efficient lighting control and high-efficient lighting devices and total heat exchangers should be used to enhance system function design. The relevant factors, such as solar energy, wind energy and geothermal energy, should be utilized to make optimized analysis on energy structure [6].

\section{GYMNASIUM DESIGN FOR THE NEW CAMPUS OF A COLLEGE OF ENGINEERING}

The gymnasium design for the new campus of a college of engineering is taken for example in this study. The detailed design analysis is shown below:

\subsection{Project Overview}

The design principles of the gymnasium of the new campus of a college of engineering are environment first and function upmost. To reach the proposed architectural effect, the comprehensiveness, ecologicalization and humanity of architectural design should be considered and analysis on the proposed creation principle and form should be done. The gymnasium is composed of competition hall, table tennis and badminton hall. It covers an area of $10635.63 \mathrm{~m} 2$, in which, the table tennis and badminton hall cover an area of $3794.49 \mathrm{~m} 2$. The competition hall is composed of contest hall (with performing and meeting function), leisure sports hall and community center for college students. The competition hall has 2,000 fixed seats and 300 to 350 moveable seats. The table tennis and badminton hall is formed by use of the space below the main stand. There are 12 table tennis venues and 6 badminton courts. Above the gymnasium are offices and fitness rooms.

\subsection{Analysis On Ecology And Energy Saving}

In the design process, since the college of architecture is located in severe cold area in Northern China, layout factor and body type factor should be considered in design. To reach heat preservation effect, detailed analysis on heat preservation system should be done. To save energy, natural resources should be fully used and different means and measures, such as exterior negative space, box energy storage space, exterior wall fabric parcel and elevated overhead roof, should be designed to create low-technology skin interface for buildings and reach low-carbon and energy saving objective. All equipment should be integrated underground and a head space of $2.5 \mathrm{~m}$ from the negative layer to the entire building should be reserved on both sides of the building. Since the breathing space has a certain distance to the insulating layer, indoor vitiated air should be discharged in design to realize free air change. Since the special geographic location of the college, indoor and outdoor factors should be considered in design to supply power and prevent heat loss due to winter monsoon and also serve as a sort of flexible decoration of the building.

\subsection{Analysis On Design Scheme}

To build a model of the gymnasium, proper length, width and height should be selected on the original design basis and proper intermediate values should be selected according to actual situation. See Table $\mathbf{5}$ for detailed values.

Based on special geographic location of the college, the shape of the gymnasium should be considered. It should be a rectangular with small shape coefficient in initial design 
process. In functional design, winter indoor activities and the scale of the college should be considered. By the use of modulus of foundation of the gymnasium and expansion of function rooms, the area of the gymnasium is limited. The overall climate impact should be considered in design, correct countermeasures should be taken according to actual situation, and layout should be done by central control form, so as to ensure the reasonability of structure layout.

\section{CONCLUSION}

Impacted by ecological sports buildings, to integrate sports culture and environment, the change between ideal objectives and ecological environment should be considered in design. Since different science fields are involved in architecture, they should be combined with sports building design mode in integration design process and system design should be done after complete objectives are made. As to the functional diversification of gymnasium, post operating management, and shape modernity and building character, the most important thing is to create ecological built environment and meet low-energy objective, and further realize design reasonability and comfort of gymnasium.

\section{CONFLICT OF INTEREST}

The authors confirm that this article content has no conflict of interest.

\section{ACKNOWLEDGEMENTS}

Declared none.

\section{REFERENCES}

[1] D. Jiang, and C. Zhang, "Ecology-based Gymnasium Design," Journal of Jilin Institute of Architecture and Civil Engineering, vol. 19, no. 10, pp. 90-93, 2011.

[2] J. Xu, and B. Hu, "Study on College-Featured Gymnasium Architecture Design - Take the Gymnasium of Nanyang Normal University for Example," Huazhong Architecture, no. 10, pp. 200-209, 2010.

[3] C. Hou, Y. Zhao, and Y. Dai, "Study on Architectural Characteristic Elements Influencing Low-energy Design of Gymnasium in Cold Region," Chinese and Overseas Architecture, vol. 09 no. 10, pp. 290-293, 2014.

[4] Z. Suo, S. Cheng, and X. Gou, "Attribute Reduction Algorithm Based on Minimal Disjunctive Normal Form," Journal of Air Force Engineering University (Natural Science Edition), vol. 1, pp. 200203, 2012.

[5] S. Guo, and Y. Chen, "Thinking on Technical Innovation of Chinese Construction Industry from the Ecological Perspective," Construction Management Modernization, vol. 19, no. 10, pp. 80-83, 2011.

[6] L. Zhang, and Q. Meng, "Actual Measurement and Analysis on Passive Energy Saving Technology of Gymnasium Buildings Take Guangdong Pharmaceutical University for Example," Journal of Civil, Architectural \& Environmental Engineering, no. 10, pp. 290-291, 2011.

Received: June 10, 2015

Revised: July 29, 2015

Accepted: August 15, 2015

(C) Zhang Zhan-Yi; Licensee Bentham Open.

This is an open access article licensed under the terms of the (https://creativecommons.org/licenses/by/4.0/legalcode), which permits unrestricted, noncommercial use, distribution and reproduction in any medium, provided the work is properly cited. 